() 2020, The Authors. Published by FASS Inc. and Elsevier Inc. on behalf of the American Dairy Science Association ${ }^{\circledR}$.

This is an open access article under the CC BY-NC-ND license (http://creativecommons.org/licenses/by-nc-nd/4.0/).

\title{
Complexity of the microRNA transcriptome of cow milk and milk-derived extracellular vesicles isolated via differential ultracentrifugation
}

\author{
Abderrahim Benmoussa, ${ }^{1,2}$ Jonathan Laugier, ${ }^{1,2}$ Charles Joly Beauparlant, ${ }^{1,3}$ Marine Lambert, ${ }^{1,2}$ \\ Arnaud Droit, ${ }^{1,3}$ and Patrick Provost ${ }^{1,2 *}$ (i) \\ ${ }^{1}$ Centre Hospitalier Universitaire de Québec Research Center/Centre Hospitalier de l'Université Laval, Quebec G1V 4G2, Canada \\ ${ }^{2}$ Department of Microbiology, Infectious Diseases and Immunology and Faculty of Medicine, Université Laval, Quebec G1V 0A6, Canada \\ ${ }^{3}$ Department of Molecular Medicine, Faculty of Medicine, Université Laval, Axe Endocrinologie - Néphrologie du Centre de recherche du Centre \\ Hospitalier Universitaire de Québec - Université Laval, Québec City, Québec, Canada
}

\section{ABSTRACT}

MicroRNAs (miRNAs) are small gene-regulatory noncoding RNA that are highly enriched in cow milk. They are encapsulated in different extracellular vesicle (EV) subsets that protect them from the extracellular milieu and the harsh conditions of the gastrointestinal tract during digestion. Here, we isolated pellets enriched in 4 different EV subsets, via differential ultracentrifugation of commercial cow milk: 12,000 $\times g(\mathrm{P} 12 \mathrm{~K})$, $35,000 \times g(\mathrm{P} 35 \mathrm{~K}), 70,000 \times g(\mathrm{P} 70 \mathrm{~K})$, and 100,000 $\times g(\mathrm{P} 100 \mathrm{~K})$. Small RNA sequencing (sRNA-Seq) analyses revealed an unprecedented level of diversity in the complete miRNA repertoire and features of unfractionated cow milk and derived EV subsets. Although 5 miRNA sequences represented more than $50 \%$ of all miRNAs, milk EV exhibited heterogeneous content of miRNAs and isomeric variants (termed isomiR): $\mathrm{P} 100 \mathrm{~K}$ EV were enriched in reference miRNA sequences, and $\mathrm{P} 12 \mathrm{~K}$ and $\mathrm{P} 35 \mathrm{~K} \mathrm{EV}$ in related isomiR. Incubation of milk EV with human cultured HeLa cells led to cellular enrichment in miRNA miR-223, which was concomitant with decreased expression of a reporter gene placed under the control of miR-223, thereby demonstrating the functionality of miR-223. These results suggest that cow milk EV may transfer their miRNAs to human cells and regulate recipient cell gene expression programming in a manner as complex as that of their miRNA transcriptome. The biological activity and relevance of the different milk EV subsets and bioactive mediators, including small noncoding RNA, in health and disease, warrants further investigation.

Key words: microRNA, bovine, exosome, extracellular vesicle, small RNA

Received April 29, 2019.

Accepted September 11, 2019.

*Corresponding author: patrick.provost@crchudequebec.ulaval.ca

\section{INTRODUCTION}

Cow milk is a highly nutritive food source for infants, children, and adults, as milk and dairy products are enriched in numerous bioactive compounds, including proteins (Ballard and Morrow, 2013), lipids (Hill and Newburg, 2015), sugars (Ballard and Morrow, 2013), and RNA (Izumi et al., 2013). Moreover, milk and its by-products are involved in preventing atopy and asthma (Sozańska et al., 2013), in modulating inflammation (Bordoni et al., 2017), and in the control of cognitive disorders ( $\mathrm{Wu}$ and Sun, 2016) and cancer risks (Thorning et al., 2016), with possible effects in prenatal (Olsen et al., 2007) and long-term postnatal growth (Melnik et al., 2013). More recently, milk microRNAs have emerged among milk bioactives (Benmoussa and Provost, 2019).

MicroRNAs (miRNAs) are small, 19- to 24-nucleotide, noncoding RNA that play a critical role in regulating messenger RNA (mRNA) translation, mainly by binding to specific sites located in the $3^{\prime}$ untranslated region of mRNA (Bartel, 2018). Harboring a high degree of phylogenetic conservation (Lee et al., 2007; Berezikov, 2011), miRNAs have been found in several organisms that are part of the human diet (Izumi et al., 2012; Baier et al., 2014; Arntz et al., 2015; Baier et al., 2015; Dever et al., 2015; Izumi et al., 2015; Title et al., 2015; Wolf et al., 2015; Benmoussa et al., 2016; Wade et al., 2016).

Each miRNA has multiple naturally occurring isomeric variants, termed isomiR (Guo and Chen, 2014). These are generated upon nucleotide substitutions, additions, or deletions to canonical miRNA sequences (Neilsen et al., 2012; Yoda et al., 2013), and their generation can be influenced by external signals (Nejad et al., 2018). Often, the most abundant miRNA isoform does not correspond to the consensus reference sequence, with specific isomiR overexpressed in disease conditions (Telonis et al., 2015). These isomiR can act in cooperation with their reference miRNA (Cloonan et al., 2011) to exert a biological activity, unraveling the 
functional and evolutionary importance of isomiR (Tan et al., 2014). Additionally, isomiR can be more effective than the reference miRNA sequence in regulating their mRNA target (Plé et al., 2012), or they may have different targets ( $\mathrm{Yu}$ et al., 2017a).

Milk is the biological fluid that is the most enriched in miRNAs (Weber et al., 2010), with miRNA and isomiR profiles depending on the health status of the cows (Sun et al., 2015). Importantly, milk miRNAs are highly resistant to the harsh conditions prevailing in this biological fluid (Pieters et al., 2015) and to different chemical and physical conditions (Izumi et al., 2012). They resist simulated digestion (Benmoussa et al., 2016; Rani et al., 2017), can possibly be transferred to human cells, and are either functional in those cells or transduced through human cell layers (Benmoussa and Provost, 2019). Such a transfer of miRNA may have resulted in an increase in the plasma concentration of specific miRNAs in human subjects who had consumed milk (Baier et al., 2014; Zempleni et al., 2017).

The surprising stability of milk miRNAs under conditions deleterious to nucleic acids is mostly due to their encapsulation within different extracellular vesicles (EV; van Herwijnen et al., 2016; Benmoussa et al., 2017; Wang, 2017; Benmoussa et al., 2019). These vesicles are membraneous nanospheres between $30 \mathrm{~nm}$ and $1 \mu \mathrm{m}$ is diameter. They are produced either by budding from the plasma membrane, in which case they are usually termed ectosomes or microvesicles (Colombo et al., 2014), or released upon invagination of multivesicular bodies and fusion of the multivesicular bodies with the plasma membrane; such EV are denominated exosomes (van Niel et al., 2018).

Known as key mediators of complex intercellular information exchanges independently of their origin or biogenesis pathway (Maas et al., 2017), EV can protect, transport in biological fluids, and deliver a usually labile cargo, including RNA, proteins, lipids, and sugars (Maas et al., 2017; Pathan et al., 2019). In milk, EV originate mainly from the mammary gland epithelial cells and other mammary gland cells, including immune cells (Reinhardt et al., 2012; Alsaweed et al., 2015; van Herwijnen et al., 2016; Benmoussa et al., 2019). Recent evidence supports the biological activity of cow milk EV in modulating immunity-related disease (Benmoussa and Provost, 2019) and possibly the methylation status of human cells through miRNA transfer (Melnik and Schmitz, 2017b).

The canonical focus on the EV subset termed exosomes has recently come into question, with the report of multiple miRNA-enriched EV subsets in commercial cow milk and other fluids (Benmoussa et al., 2017). The peculiar enrichment of cow milk in these understudied, usually discarded EV subsets suggests an underestima- tion of the bioactivity of milk EV. Moreover, so far, most of the studies currently available have focused on raw milk, rather than on commercial pasteurized milk intended for human consumption.

Here, we have (1) unveiled the relatively complex miRNA profile of unfractionated commercial pasteurized cow milk and derived EV subsets via small RNA sequencing (sRNA-Seq), (2) documented the enrichment of human cultured cells in miR-223 upon coincubation with usually discarded milk EV, and (3) observed a decreased expression of a reporter gene placed under the control of miR-223, which attested to the functionality of miR-223.

\section{MATERIALS AND METHODS}

\section{Dairy Milk Samples}

We used commercial skimmed filtered dairy milk (PurFiltre, Lactantia, Toronto, Canada; http://www .lactantia.ca/foodproduct/lactantia-purfiltre-skim -milk/) bought at a local grocery store in Quebec City, Canada. Three cartons of milk with different expiration dates were mixed into 1 milk solution for isolating $\mathrm{EV}$.

\section{Sedimentation of Dairy Milk EV by Differential Ultracentrifugation}

Milk EV were obtained by following a previously described protocol, with slight modifications, that allows quick isolation of milk EV with very few contaminating proteins (Benmoussa et al., 2016, 2017, 2019). We mixed $200 \mathrm{~mL}$ of dairy milk with 1 volume of $2 \%$ sodium citrate in water that had been filtered with 0.22 $\mu \mathrm{m}$ membrane microfilters (Corning, Corning, NY). The samples were subjected to successive differential ultracentrifugation steps at $12,000 \times g(12 \mathrm{~K})$ for $2 \mathrm{~h}$, $35,000 \times g(35 \mathrm{~K})$ for $2 \mathrm{~h}$, then $70,000 \times g(70 \mathrm{~K})$ and $100,000 \times g(100 \mathrm{~K})$ for $1 \mathrm{~h}$ each at $4^{\circ} \mathrm{C}$ in a Sorvall WX TL-100 ultracentrifuge, equipped with a SureSpin 630 Rotor (Sorvall, through Thermo Fisher Scientific, Waltham, MA). After each step, pellets were suspended in $1 \mathrm{~mL}$ of $0.22-\mu \mathrm{m}$ filtered sterile PBS, $\mathrm{pH} 7.4$, before RNA isolation.

\section{RNA Isolation and Sequencing}

$\boldsymbol{R N A}$ Isolation. Total RNA from milk or milk pellets was isolated using Trizol LS (Thermo Fisher Scientific) following the manufacturer's recommendations. Total RNA was then resuspended in diethylpyrocarbonate (DEPC)-treated, nuclease-free water (Invitrogen, Carlsbad, CA) before RNA purification and on-column DNase treatment using RNeasy minikit (Qiagen, Hilden, Germany), according to the manu- 
facturer's protocol. Total RNA was shipped on dry ice to the ArrayStar sequencing platform (Rockville, MD).

Library Preparation. The purity, quality, and concentration of total RNA samples were determined with NanoDrop ND-1000 (Thermo Fisher Scientific) and 2100 Bioanalyzer (Agilent, Santa Clara, CA). Total RNA of each sample was used to prepare the miRNA sequencing library, which included the following steps: (1) 3'-adapter ligation, (2) 5'-adapter ligation, (3) cDNA synthesis, (4) PCR amplification, and (5) size selection of approximately 130 to $150 \mathrm{bp}$ of PCR-amplified fragments (corresponding to approximately 15 to $35 \mathrm{nt}$ of small RNA). The complete libraries were quantified by Agilent 2100 Bioanalyser.

$s \boldsymbol{R} \boldsymbol{N A}$-Seq. The samples were diluted to a final concentration of $8 \mathrm{p} M$ and denatured as single-stranded DNA. Cluster generation was performed on the Illumina cBot using TruSeq Rapid SR cluster kit (\#GD402-4001, Illumina, San Diego, CA). Afterward, the clusters were sequenced for 51 cycles on Illumina HiSeq 2000, using TruSeq Rapid SBS Kits (\#FC-402-4002, Illumina), as per the manufacturer's instructions.

Bioinformatics Analysis. The clean reads that passed the quality filter were processed to remove the adaptor sequence as the trimmed reads. All analyses displayed here were provided through the ArrayStar standard analysis pipeline and refined using $\mathrm{R}$ ( R Foundation for Statistical Computing, Vienna, Austria). Small RNA biotypes were determined by mapping trimmed reads against bovine noncoding RNA database (Bos_taurus.UMD3.1.ncrna, bovinegenome. org; Elsik et al., 2016) using Blastn tool (National Library of Medicine, National Center for Biotechnology Information, https://blast.ncbi.nlm.nih.gov/Blast.cgi). For miRNA and isomiR analysis, trimmed reads were aligned to miRBase pre-microRNAs database (miRbase release 22.1, http://www.mirbase.org/). MicroRNA read counts were normalized as read counts per million (RPM) miRNA alignments. Sequences known to be contaminant confounders from RNA isolation procedures were discarded (Heintz-Buschart et al., 2018).

\section{Cell Experiments}

Cell Culture. Human HeLa cells (ATCC, Manassas, VA) were cultured in Dulbecco's modified Eagle's medium (Wisent, St-Bruno, Canada) supplemented with exosome-free fetal bovine serum (System BioSciences, Palo Alto, CA) and maintained at $37^{\circ} \mathrm{C}$ under $5 \% \mathrm{CO}_{2}$.

Dual Luciferase Reporter Gene Constructs and Activity Assays. Reporter gene activity assays were performed as previously described (Pépin et al., 2012; Plé et al., 2012; Laffont et al., 2013). A btamiR-223 reporter construct was created by inserting a sequence complementary to bta-miR-223 downstream of the open reading frame encoding for the Rluc reporter gene, in the XhoI/NotI restriction sites of psiCHECK-2 vector (Promega, Madison, WI), in which 2 luciferase genes (Firefly and Renilla), driven by separate promoters, are expressed. The constructs were verified by DNA sequencing. The psiCHECK-2 vector (Promega) expressed Firefly luciferase (Fluc) gene is an internal control.

Co-Incubation with Milk $\boldsymbol{E} V$. For all experiments, $1.5 \times 10^{5}$ cells were seeded in sterile 6 -well plates. For co-incubation of the cells with milk EV, the medium was changed to milk EV-enriched medium $8 \mathrm{~h}$ after seeding and left for $48 \mathrm{~h}$. For dual luciferase assays, after overnight attaching, cells were transfected with the reporter gene construct using Lipofectamine 2000 (Thermo Fisher), following the manufacturer's instructions. Six hours later, the culture medium was changed to milk EV-enriched medium, which was left for $48 \mathrm{~h}$.

\section{Molecular Biology Analysis in Cell Experiments}

$\boldsymbol{R N A}$ Isolation. Cells were suspended in $1 \mathrm{~mL}$ of TRIzol Reagent, and RNA was isolated according to the manufacturer's instructions, followed by DNase I digestion (Invitrogen).

$\boldsymbol{R T}-q \boldsymbol{P C R}$. One microgram of total RNA was used for reverse transcription (RT) using the MiScript II RT kit (Qiagen). After diluting the cDNA (1 to 10), RT-qPCR was performed using specific primers (MiScript Primer Assay, Qiagen) and the SsoAdvanced SYBR Green Supermix (Bio-Rad, Hercules, CA) in 96-well MicroAmp plates (Applied Biosystems through Thermo Fisher Scientific). MicroRNA expression was normalized using the $\Delta \Delta \mathrm{Cq}$ method (Bustin et al., 2009) and small nucleolar RNA RNU6 as a housekeeping gene (Schwarzenbach et al., 2015), based on MIQE guidelines (Supplemental File S1; https://doi.org/10.3168/jds.2019-16880).

Dual Luciferase Assay. Renilla luciferase (Rluc) and Fluc activities were measured after washing the cells twice with $0.22-\mu \mathrm{m}$ filtered sterile PBS and cells lysis with Dual Glo luciferase reagents (Promega), following the manufacturer's instructions. Light emission was measured using a luminometer (Dynex Technologies, Chantilly, VA).

\section{Statistical Analysis}

All statistical analyses were performed using Prism 7 (GraphPad Software Inc., La Jolla, CA). In vitro experiments were performed in biological replicates (n $=3$ ) with type error $\alpha$ set to $0.05(5 \%)$ and with a $P$-value below 0.05 considered as significant. Statistical significance was determined by one-way ANOVA with Tukey's post-hoc correction for multiple comparisons. 


\section{Illustrations}

Figures were generated using $\mathrm{R}$ ( $\mathrm{R}$ Foundation for Statistical Computing), Inkscape software (inkscape. org), and Prism 7 (GraphPad Software Inc.).

\section{RESULTS}

\section{Commercial Cow Milk Contains Different Small RNA, Including Numerous MiRNAs}

Analysis of commercial cow milk via sRNA-Seq revealed that the majority $(67.1 \%)$ of small RNA were between 20 and 24 nt in length (Figure 1A). We also observed that most of the defined small RNA found in commercial cow milk were miRNAs, which represented more than $3 \times 10^{5} \mathrm{RPM}$ (Figure 1B). However, most of the clean read sequences were undefined small RNA (Figure 1B). The minimum detection threshold (i.e., the lowest RPM to detect the least expressed miRNA in these data sets) was around 0.03 RPM (Figure 1C). Fourteen miRNAs represented more that $80 \%$ of all reads (Figure 1C and D), with bta-let-7a being the most abundant (15.1\% of all miRNAs), followed by bta-miR-21 and bta-miR-30a (approximately $12 \%$ each; Figure 1D).

We compared the small RNA data set of our commercial cow milk with previously published sequencing data on raw and pasteurized wheys ( $\mathrm{Li}$ et al., 2016), raw milks (Chen et al., 2010; Sun et al., 2015), and primary mammary epithelial cells (pMEC-HH and pMEC-LL; Shen et al., 2016). MicroRNA profiles of our commercial cow milk were closer to those of the raw milks than to pMEC-LL or pMEC-HH, and even less related to raw or pasteurized whey, suggesting that milk whey contains only a specific subset of milk miRNAs (Supplemental Figure S1; https://doi.org/10 .3168/jds.2019-16880).

Interestingly, the 5 most related samples (raw milks, commercial milk, and pMEC cells) had 94 miRNAs in common, suggesting that the miRNAs contained in milk derive from mammary gland epithelial cells (Figure $1 \mathrm{E}$ ). Only 25 and 56 miRNAs were found in either of the raw milks, with 5 shared miRNAs, suggesting that certain miRNAs may be lost during processing or may differ between cows (Figure 1E). Only 50 miRNAs were found in the commercial cow milk, likely because it is a pool from multiple cows (Figure 1E). Thirty-four miRNAs were found only in milks and not in pMEC cells, suggesting the existence in milk of miRNAs that are not derived from mammary gland epithelial cells (Figure 1E). The pMEC cells shared 37 specific miRNAs that were not found in any milk samples (Figure $1 \mathrm{E})$, which supports a selective secretion of some miRNAs in milk. The entire data set and comparison are available as Supplemental File S2 (https://doi.org/10 .3168/jds.2019-16880).

All together, these results suggest that commercial cow milk contains numerous small RNA, among which miRNAs compose most of the sequences. Very few miRNAs monopolized most of the reads, with 5 miRNAs comprising $50 \%$ of all sequences. Finally, comparison with other sequencings from the literature suggest that milk is a complex fluid, enriched in different miRNAs that might not all survive processing, and which could be specifically secreted by mammary gland epithelial cells and other cell types.

\section{Milk EV Subsets Separated by Differential Ultracentrifugation Have Different Small RNA Contents}

We have previously reported that commercial cow milk contains multiple EV subsets that can be separated using differential ultracentrifugation (Benmoussa et al., 2017, 2019), and that these have different protein contents (Benmoussa et al., 2019). We thus aimed to investigate the miRNA content of non-fractioned commercial cow milk as well as that of milk fractioned into 4 pellets (centrifuged at $12,000 \times g, \mathbf{P} \mathbf{1 2 K} ; 35,000 \times g$, P35K; 70,000 $\times g, \mathbf{P 7 0 K}$; and 100,000 $\times g, \mathbf{P 1 0 0 K )}$, using our previously reported methodology (Benmoussa et al., 2017, 2019). These different milk EV subsets were analyzed via sRNA-Seq.

The small RNA profile of all samples were enriched in sequences around $22 \mathrm{nt}$, a length that usually corresponds to miRNA (Figure 2A). This was particularly the case for the P70K and P100K samples (Figure 2A), whereas P12K and P35K had secondary peaks around 18 and $27 \mathrm{nt}$, suggesting a more heterogeneous population of small RNA (Figure 2A).

When looking at small RNA biotypes in each pellet, we found a specific enrichment of miRNAs in P70K and P100K (47 to $67 \%$ of all sequences), whereas only 24 and $30 \%$ of all sequences were miRNAs in the P12K and P35K samples, respectively (Figure 2B). Most undefined sequences were associated with $\mathrm{P} 12 \mathrm{~K}$ and P35K samples. Other small RNA biotypes were found in all samples, with misc-RNA and snoRNA being highly enriched in $\mathrm{P} 12 \mathrm{~K}$ and $\mathrm{P} 35 \mathrm{~K}$, and rRNA fragments being higher in P100K (Figure 2B). Very few non-miRNA sequences were present in P70K (Figure 2B).

These data revealed high similarity between P12K and P35K samples, whereas P70K and P100K represented distinct populations with specific small RNA profiles. Because small RNA in milk pellets are contained within and protected by EV (Benmoussa et al., 2017), these results also suggest the specific enrichment of certain small RNA biotypes in certain EV subsets. 
A

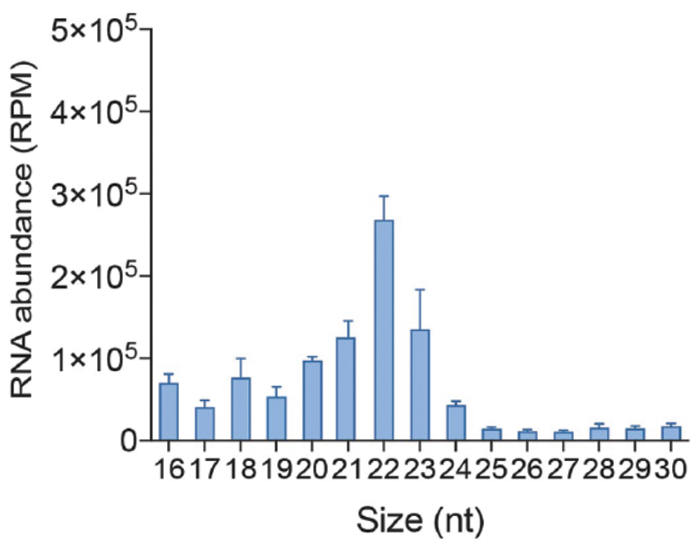

C

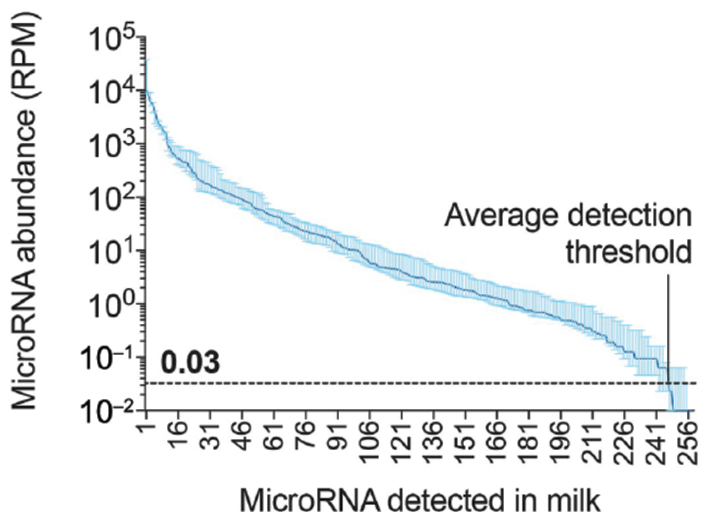

B

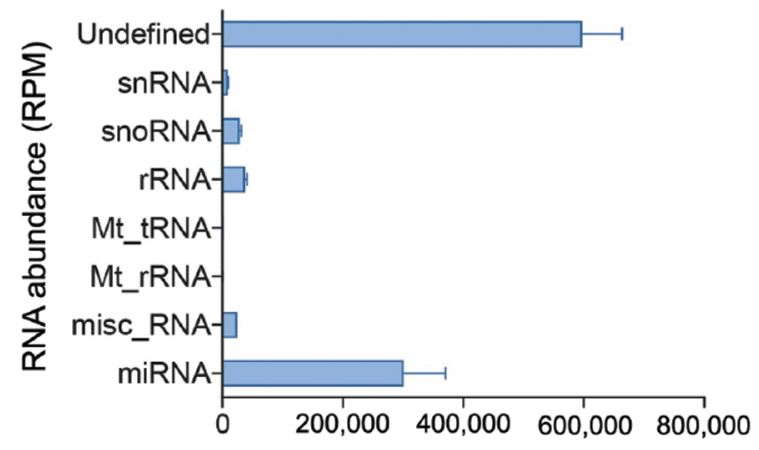

D

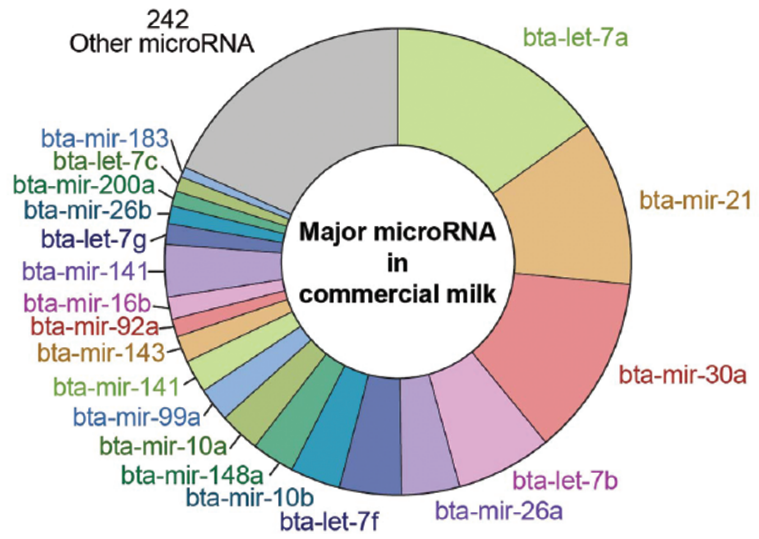

E

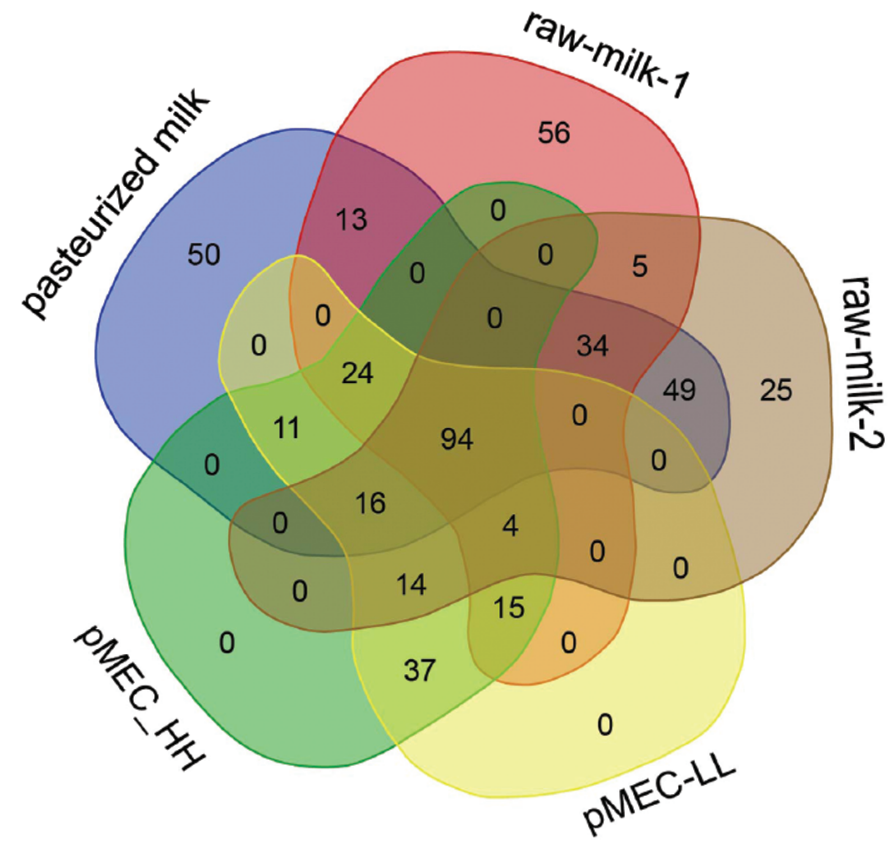

Figure 1. Small RNA and microRNA (miRNA) profile of commercial cow milk. Total RNA from $100 \mathrm{~mL}$ of cow milk was isolated with Trizol LS (Thermo Fisher Scientific, Waltham, MA) and subjected to small RNA sequencing ( $\mathrm{n}=3$ independent experiments). (A) Size distribution of the small RNA, expressed as reads per million (RPM). (B) Small RNA biotype abundance (RPM). The data are displayed as average \pm SD. (C) Number of different miRNAs detected in milk, expressed as RPM, defining average detection threshold. (D) Most abundant miRNAs in commercial cow milk (percent of total). (E) Venn diagram comparing commercial pasteurized cow milk miRNA profile (n $=3$ ) with 2 previously published database of raw milks (raw-milk-1, Sun et al., 2015; raw-milk-2, Chen et al., 2010) and primary mammary gland epithelial cell miRNA (pMEC-HH and pMEC-LL; Shen et al., 2016). 
A

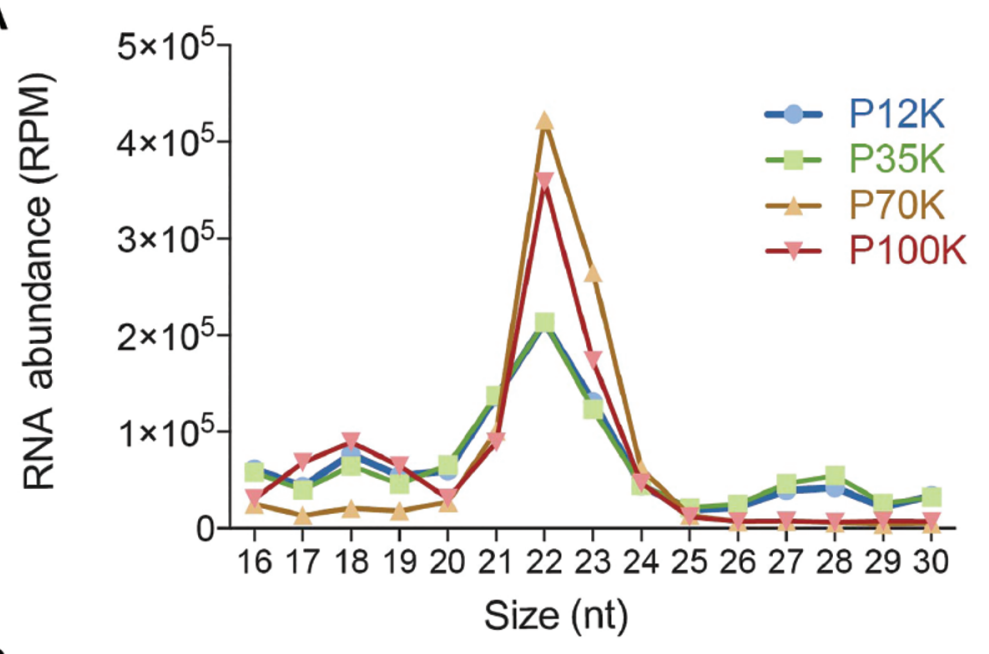

B

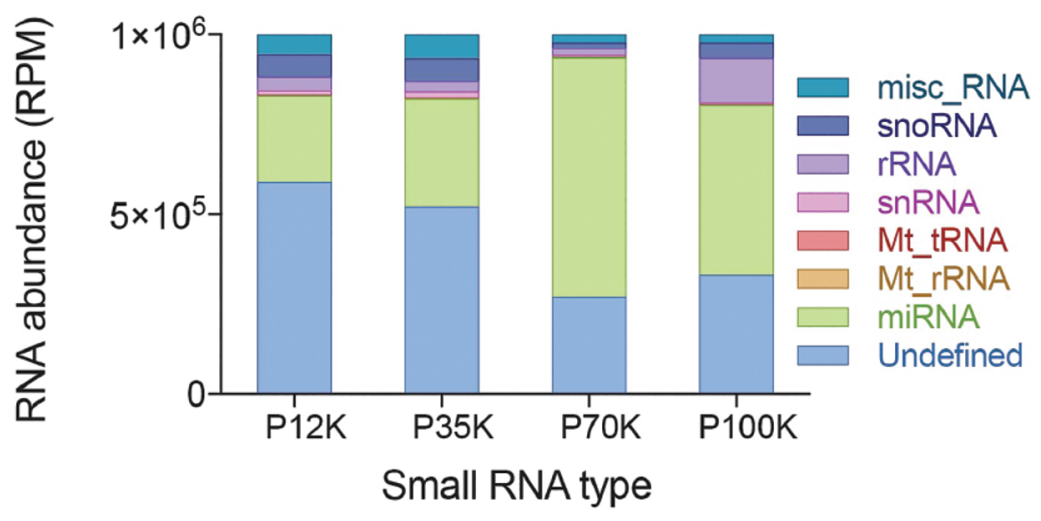

C

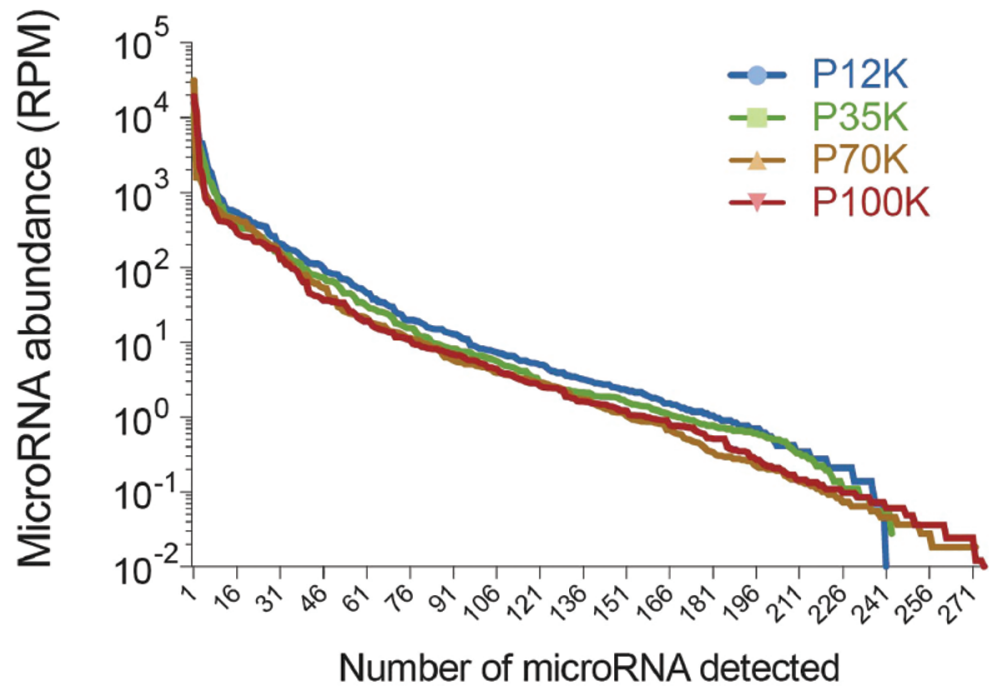

Figure 2. Small RNA profiles of milk EV subsets. One hundred milliliters of commercial cow milks were fractionated into 4 pellets via sequential ultracentrifugation at 12,000 $\times g(\mathrm{P} 12 \mathrm{~K}), 35,000 \times g(\mathrm{P} 35 \mathrm{~K}), 70,000 \times g(\mathrm{P} 70 \mathrm{~K})$, and 100,000 $\times g(\mathrm{P} 100 \mathrm{~K} ; \mathrm{n}=3$ independent experiments). The 3 pellets obtained from each ultracentrifugation speed were pooled to obtain 4 biological pools; total RNA from $1 \mathrm{~mL}$ of each pool was isolated with Trizol LS (Thermo Fisher Scientific, Waltham, MA) and subjected to small RNA sequencing. (A) Length distribution (in nucleotides, nt) of the small RNA in each pellet, in reads per million (RPM). (B) Small RNA biotype abundance (RPM) in each pellet. (C) Number of different microRNAs detected in milk pellets (RPM), defining average detection threshold. 


\section{Different EV Subsets Contain Different MiRNAs}

A few miRNAs (14 to 16) monopolized most of the reads in the samples of non-fractioned milk (Figures $2 \mathrm{C}$ and $3 \mathrm{C}$ ). Regarding the fractionated milk samples, around 230 different miRNAs were detected in the P12K and P35K pellets, whereas approximately 270 miRNAs were present in P70K and P100K (Figure 2C). The 4 pellets shared 200 miRNAs, suggesting their common origin (Figure 3A). Fourteen miRNAs were specific to the P12K and P35K pellets (Figure 3A); up to 16 were specific to P70K and 22 to P100K (Figure 3A). These last 2 pellets have 24 miRNAs in common that were not shared with P12K or P35K (Figure 3A). On the other hand, P13K and P35K shared 6 miRNAs that were not found in the P70K or P100K pellets (Figure 3A). Along with the clustering of the 4 pellets based on miRNA content (Figure 3B), these results confirmed the close relationship between $\mathrm{P} 12 \mathrm{~K}$ and $\mathrm{P} 35 \mathrm{~K}$ and the distinct populations represented by $\mathrm{P} 70 \mathrm{~K}$ and $\mathrm{P} 100 \mathrm{~K}$.

This is further validated when looking at the most enriched miRNAs for each pellet: 4 miRNAs (bta-let7a, bta-miR-30a, bta-miR-21, and bta-let7b) represented up to $50 \%$ of all miRNA sequences in the P12K and P35K data sets, with a comparable distribution between the 2 pellets (Figure 3C). Of the remaining reads, $25 \%$ were monopolized by 10 miRNAs (Figure $3 \mathrm{C})$. By contrast, the miRNA profile of P70K was very different, with bta-let7a the most abundant miRNA, representing, along with 9 others, $50 \%$ of the sequences (Figure 3C). For P100K, only 2 miRNAs monopolized $50 \%$ of the sequences, with bta-miR-10b corresponding to more than $45 \%$ of them (Figure 3C).

These results extend previous conclusions to the entire small RNA transcriptome and support the existence of at least $3 \mathrm{EV}$ subsets in milk (P12K and P35K, P70K, and P100K), which sediment at different speeds and contain different miRNAs. Moreover, and despite the diverse array of miRNAs found in milk pellets, a discrete number of miRNAs represented most of the sequences. This is in accordance with previous observations on non-fractioned milk (Figure 1), which provides further evidence of the specific secretion of certain miRNAs in milk.

\section{Different EV Subsets Contain Different IsomiRs}

In all biological samples, each miRNA exists in various isomeric forms, termed isomiRs. These sequences differ slightly from their related reference miRNA sequences by shifts, additions, or deletions at their $3^{\prime}$ or $5^{\prime}$ ends, or by mutations in their sequences (Gebert and MacRae, 2019). Thus we also investigated isomiR enrichment and distribution among the ultracentrifugation pellets.
In $\mathrm{P} 12 \mathrm{~K}$ and $\mathrm{P} 35 \mathrm{~K}$, most miRNAs (approximately $75 \%$ ) were found in their isomeric form; their reference miRNA sequences represented only approximately $15 \%$ of all miRNAs (Figure 4A). On the other hand, P70K and P100K had higher levels of reference miRNAs, which reached up to $55 \%$ in P100K, suggesting a specific loading of reference miRNAs in EV of P100K (Figure 4A).

The vast majority ( 80 to $90 \%$ ) of the miRNA isoforms observed in all pellet were isoforms with no mismatch (mutation; Figure 4B). Interestingly, across all pellets, 164 miRNAs were only found as isomiR, with no occurrence of the reference sequence among our sRNA-Seq data (data not shown).

We calculated the ratio of the reference miRNAs to all the sequences for all miRNAs, with the aim of investigating any specific reference miRNAs or isomiR enrichment in the pellets (Figure 4C). Again, clustering analysis confirmed that $\mathrm{P} 12 \mathrm{~K}$ and $\mathrm{P} 35 \mathrm{~K}$ were highly related to each other, but $\mathrm{P} 70 \mathrm{~K}$ and $\mathrm{P} 100 \mathrm{~K}$ were distinct when considering isomiR, increasing the complexity of the EV and miRNA content of commercial cow milk (Figure 4C). These data also confirmed that different milk EV subsets harbor a different isomiR content, possibly because these EV are generated through different mechanisms.

The diversity of miR-30a isomiR and that of their predicted mRNA targets illustrate how isomiR may influence gene expression in a manner different from their reference miRNA sequences (Supplemental Figure S2; https://doi.org/10.3168/jds.2019-16880).

\section{Milk EV Enrich Human Cultured HeLa Cells in Functional miR-223}

We found a significant, greater than 3-fold enrichment of HeLa cells in miR-223 upon co-incubation only with P12K EV (versus PBS control; $P<0.01, \mathrm{n}=3$, Figure 5A). The increase in miR-223 observed upon coincubation of HeLa cells with P35K EV did not reach the significance threshold of 0.05 after 3 independent experiments $(P=0.058$; Figure $5 \mathrm{~B})$.

Those EV that sediment at low centrifugation speed are usually neglected, often considered as contaminants and readily discarded. We have shown, here and previously (Benmoussa et al., 2016, 2017, 2019), that P12K and P35K pellets seem to be closely related. Therefore, we chose to pool them (simplified as P35K) and further purify the EV they contain using an iodixanol density gradient (Figure 5B). Using the isomiR data, we designed a dual luciferase reporter gene assay, in which the Rluc gene was placed under the regulatory control of miR-223 through the 
A

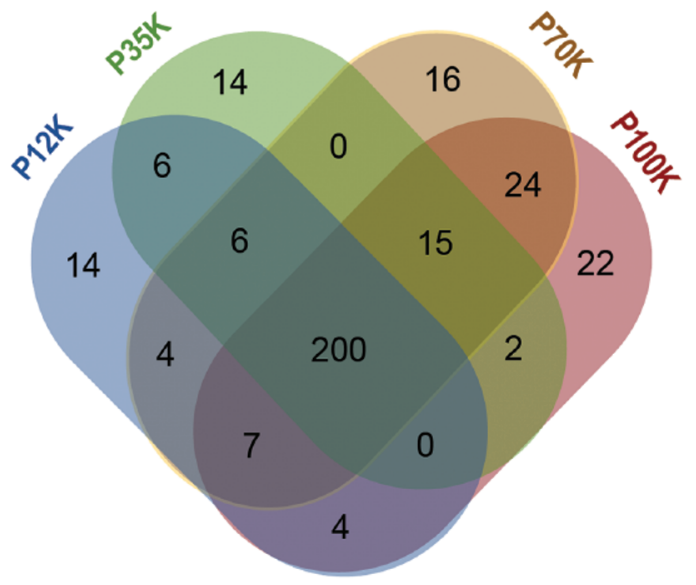

B
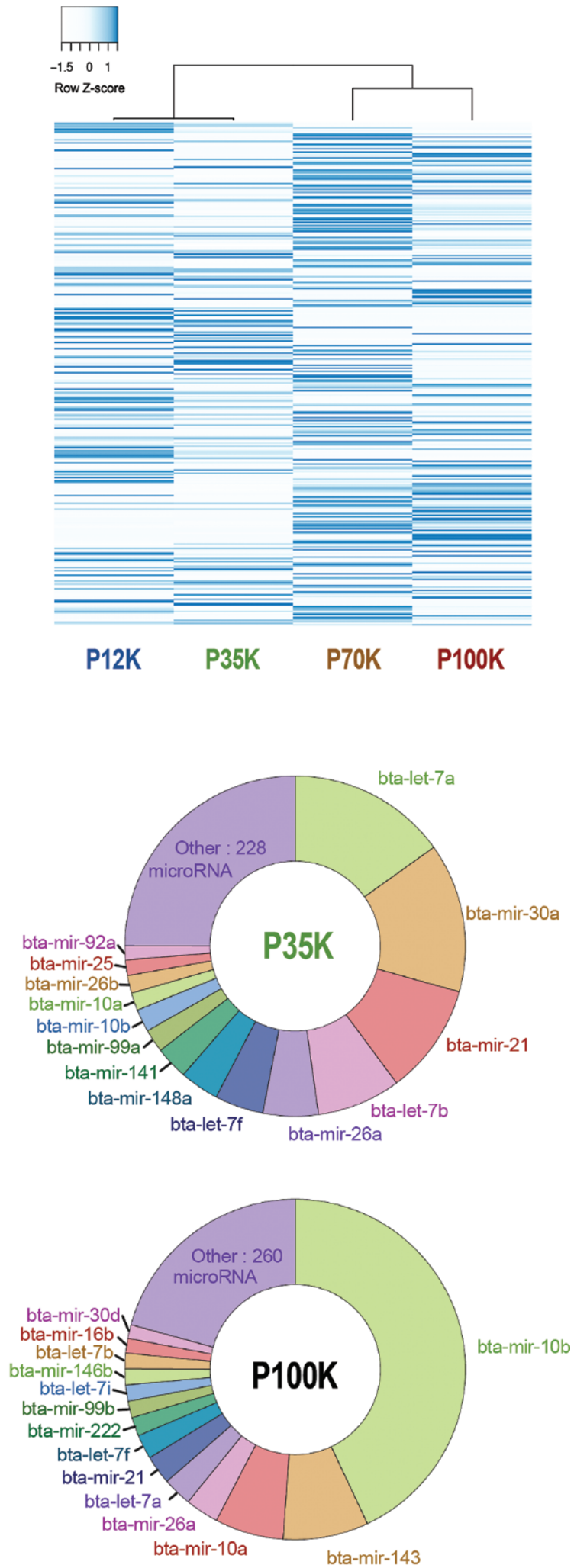

Figure 3. MicroRNA (miRNA) distribution in milk extracellular vesicle (EV) subsets. Cow milk samples were fractionated via differential ultracentrifugation [at 12,000 $\times g(\mathrm{P} 12 \mathrm{~K}), 35,000 \times g(\mathrm{P} 35 \mathrm{~K}), 70,000 \times g(\mathrm{P} 70 \mathrm{~K})$, and $100,000 \times g(\mathrm{P} 100 \mathrm{~K})$ ] and analyzed by small RNA sequencing ( $\mathrm{n}=3$ independent experiments). (A) Venn diagram displaying the number of miRNAs shared or not shared between the 4 commercial pasteurized cow milk pellets. (B) Comparison of milk EV miRNA profiles and clustering of milk EV subsets. (C) Most abundant miRNAs in each commercial cow milk pellet (percent of total). 
A

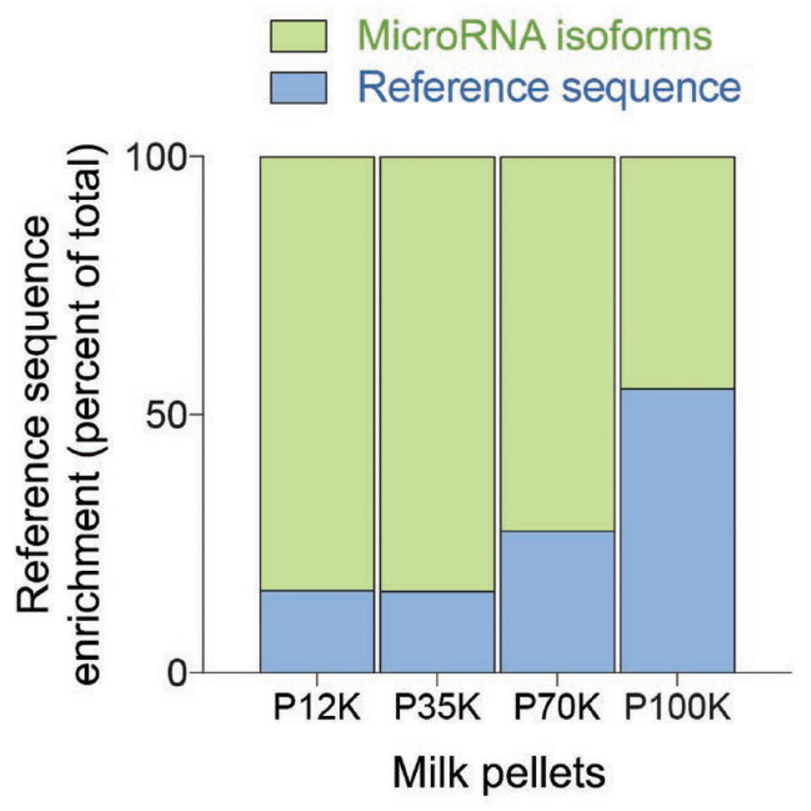

B

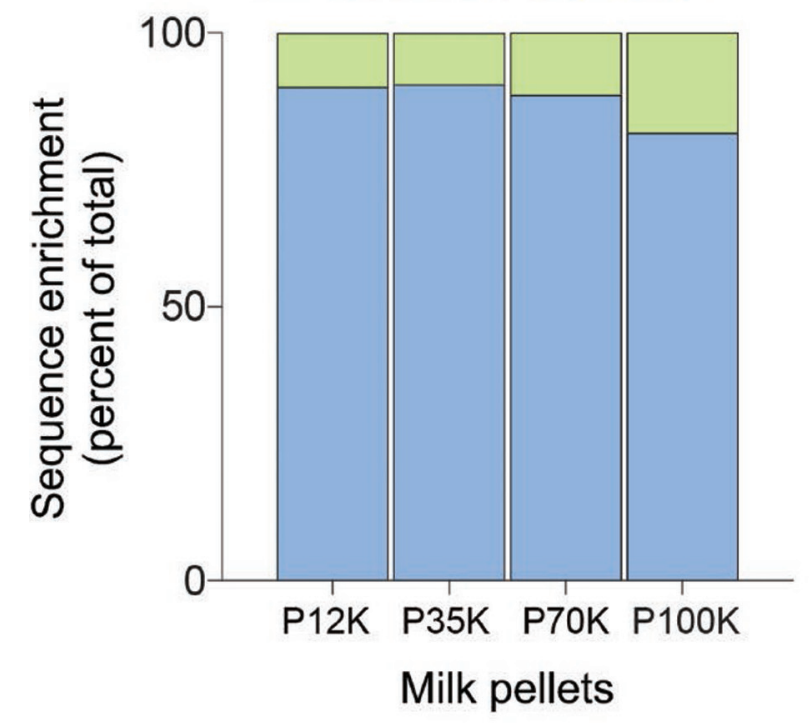

C
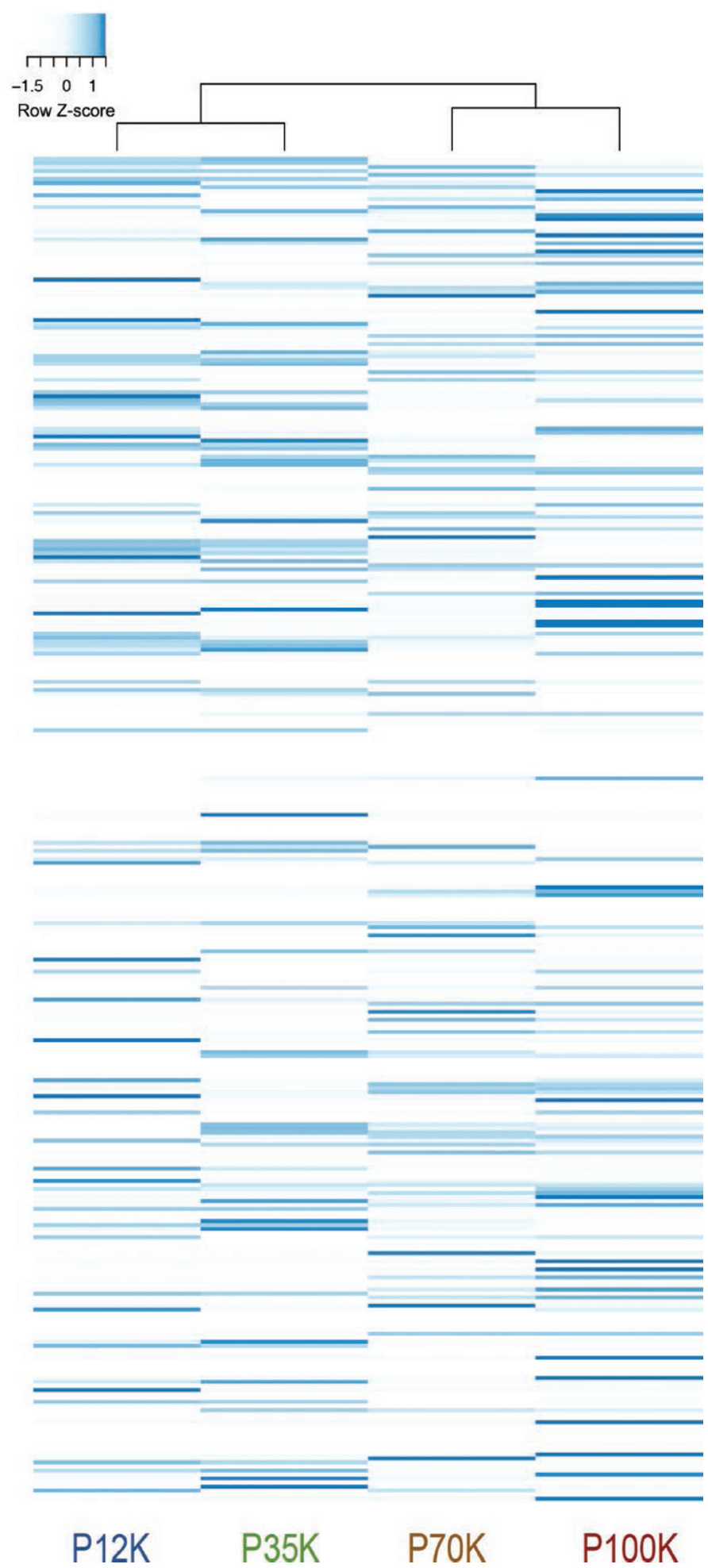

Figure 4. MicroRNA isomer (isomiR) distribution in milk extracellular vesicle (EV) subsets. Commercial cow milk samples were fractionated by differential ultracentrifugation [at 12,000 × $g(\mathrm{P} 12 \mathrm{~K}), 35,000 \times g(\mathrm{P} 35 \mathrm{~K}), 70,000 \times g(\mathrm{P} 70 \mathrm{~K})$, and $100,000 \times g(\mathrm{P} 100 \mathrm{~K})]$ and analyzed by small RNA sequencing ( $\mathrm{n}=3$ independent experiments). IsomiR are isomeric sequences of a specific reference microRNA (miRNA). (A) Relative abundance of miRNA reference sequences and their related isomiR (in percent of total miRNAs) in milk EV subsets. (B) Relative abundance of isomiR type (1-mismatch or 0-mismatch), in percent of total isomiR for each miRNA. (C) Comparison of milk EV isomiR profiles and clustering of milk EV subsets. 
introduction of a perfectly complementary binding site in its $3^{\prime}$ untranslated region. The Fluc reporter gene is constitutively expressed and was used to nor- malize the gene expression data. A similar construct, but with a mutated (scrambled) bta-miR-223 binding site, was used as a negative control (Figure 5C).
A

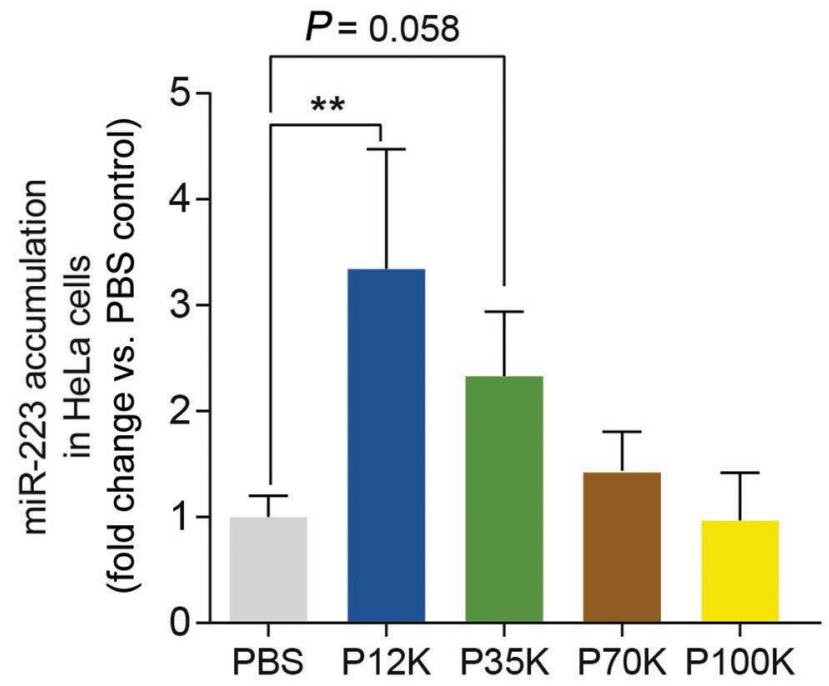

C
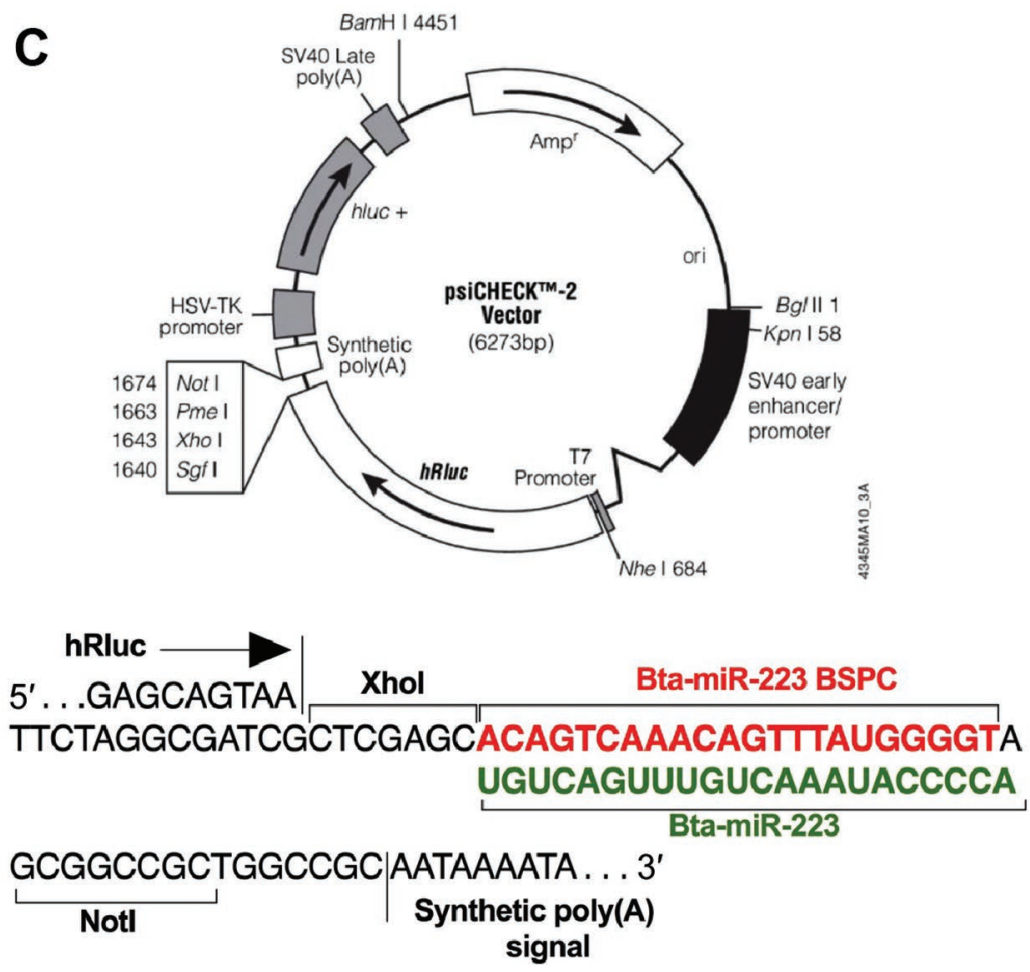

B

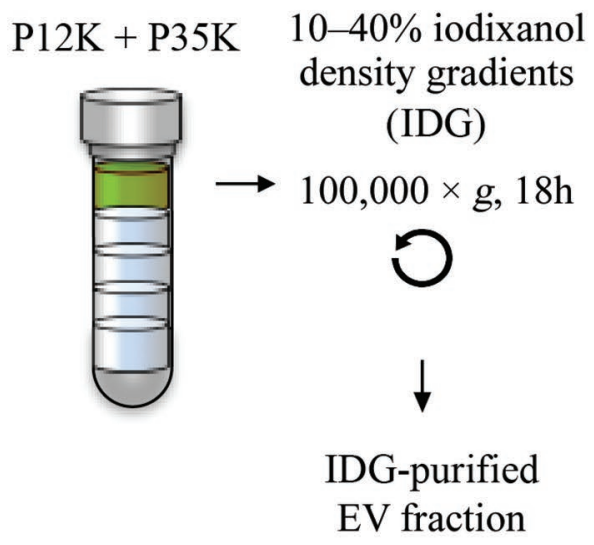

D

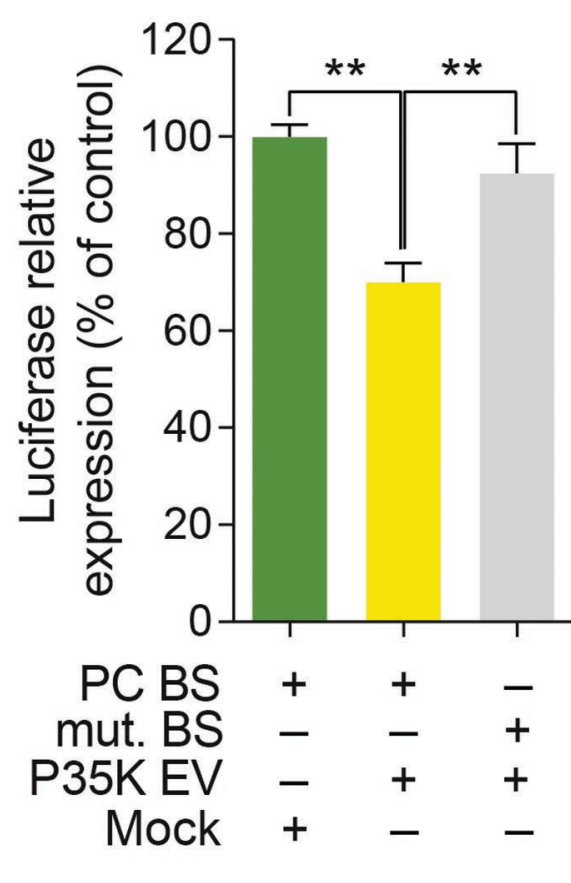

Figure 5. Milk extracellular vesicles (EV) enrich human cultured HeLa cells in functional miR-223. Commercial cow milk samples were fractionated via differential ultracentrifugation [at 12,000 $\times g(\mathrm{P} 12 \mathrm{~K}), 35,000 \times g(\mathrm{P} 35 \mathrm{~K}), 70,000 \times g(\mathrm{P} 70 \mathrm{~K})$, and 100,000 $\times g(\mathrm{P} 100 \mathrm{~K})]$, and each pellet was layered on an iodixanol density gradient (IDG) to further purify the EV ( $\mathrm{n}=3$ independent experiments). (A) P12K and P35K milk EV enrich human cultured HeLa cells in miR-223. (B) Schematic representation of the IDG purification approach to further purifying milk EV. (C) Schematic representation of the dual luciferase reporter gene activity assay in which Rluc (Renilla luciferase) expression is responsive to bta-miR-223. (D) Milk P35K EV suppressed Rluc reporter gene expression (relative to firefly luciferase) via recognition of the miR-223 binding site by miR-223. ${ }^{* *} P<0.01$. $\mathrm{PC}=$ perfectly complementary; $\mathrm{BS}=$ binding site; mut = mutated. 
After transfecting the dual Rluc and Fluc reporter construct in HeLa cells, which are virtually devoid of miR-223, the cells were co-incubated for $48 \mathrm{~h}$ with P35K EV mix (P12K + P35K). Reporter gene expression was significantly reduced by $30 \%$ by P35K EV, compared with PBS control $(P<0.01, \mathrm{n}=3$; Figure $5 \mathrm{D})$, suggesting that P35K milk EV can mediate the enrichment of human cells in functional, gene regulatory miR-223. This gene regulatory effect was lost when the binding site to miR-223 was mutated, thereby confirming the specific activity of miR-223 on the reporter gene (Figure 5D).

These results suggest that cow milk EV sedimenting at $12,000 \times g$ and $35,000 \times g$, and thus different from the more commonly studied high-density extracellular vesicles, or exosomes, can be internalized by human cells and mediate the transfer of miRNAs that are functional in regulating gene expression.

\section{DISCUSSION}

In this study, we found that commercial cow milk contained a diverse array of small RNA and miRNAs, but only a small number of miRNAs monopolized most sequencing reads. We also found numerous unknown sequences. Among those are likely numerous tRNA fragments, which were not indexed in the databases available for bovine samples (Keam and Hutvagner, 2015). Other kinds of bovine small RNA are also missing from these databases, mainly because most of the work on small RNA is performed on human and mouse samples. It would, therefore, be important to develop bovine small RNA databases to ensure mapping of these unknown sequences. Because milk can contain viruses, bacteria, and possibly bacterial outer membrane vesicles, it is also possible that part of these unknown sequences is of viral or bacterial origin (Baumgartener et al., 1977; Kulp and Kuehn, 2010; Pang et al., 2018). Integration of our data with previously published data sets suggested epithelial origin of milk miRNAs. Although informative, such an approach needs to be taken with care because of the differences that might exist between cow breeds (Wicik et al., 2016).

Usually, the most abundant miRNA in cow milk is bta-miR-148a (Benmoussa and Provost, 2019), whose possible influences on health have been thoroughly discussed previously (Melnik and Schmitz, 2017a, b). However, in the present study, bta-miR-148a was not the most abundant miRNA. This difference likely pertains to the difference in milk sources. In most previous studies, researchers used raw milk rather than commercial milk. Because milk processing highly affects EV and miRNA profiles and survivability, it is most likely that part of miR-148a is lost during milk processing (Izumi et al., 2012; Yu et al., 2017b; Benmoussa and Provost, 2019). Another possibility, apart from geographical differences in milk content that may also occur, is that most of the previous research focused solely on a small proportion of milk EV (i.e., the exosome subset), while possibly discarding the $12 \mathrm{~K}$ and $35 \mathrm{~K}$ fractions that are the most enriched in miR-148a. Also, for the latter fractions, we cannot exclude the possibility that ultracentrifugation might have led to the loss of certain EV containing miR-148a. Therefore, because this miRNA and others might affect consumers (Zempleni et al., 2017), it is important to compare how different milks and milk processing techniques (pasteurization, ultraheat sterilization, filtering, ultrafiltration, pascalization, and so on) and EV isolation methods (ExoQuick, ultracentrifugation, ultrafiltration, and the like) may affect the miRNA and EV profiles of milk intended for human consumption (Bogahawaththa et al., 2018). It will be important to replicate the current study with untreated raw cow milk to get a clearer picture of the physiology of milk-derived EV and miRNA.

In this study, we found that different milk EV contained a different repertoire of small RNA and miRNAs, with numerous miRNAs in common, suggesting a common origin of these EV. This is supported by previous work on milk miRNAs (Li et al., 2012; Alsaweed et al., 2016; Shen et al., 2016; Hou et al., 2017; Ju et al., 2018; Luoreng et al., 2018), which showed that a single cell type can secrete different EV subsets with different miRNA content (Lässer et al., 2017; Chiou et al., 2018). Cow milk EV subsets also contained different miRNAs and isomiR, the isomeric forms of miRNA, suggesting that different milk EV might exert different biological effects if milk miRNAs were transferred to recipient human cells. Therefore, we deem it important, for the milk EV research community, to expand the scope of their studies beyond the EV subset known as exosomes, especially when considering milk miRNAs, and to more thoroughly investigate the breadth of EV subsets present in milk and other biological fluids. It would also be of interest to replicate internalization experiments with non-exosomal milk EV to assess whether these are internalized in the body by transcytosis, as are exosomes (Betker et al., 2019), or whether they are repackaged into chylomicrons or other extracellular vesicles or bodies.

Interestingly, bta-miR-223 accumulated in human cells incubated with milk EV in vitro, which correlated with decreased activity in the dual luciferase reporter gene specifically designed to be targeted by bta-miR-223. We chose to study this miRNA, specifically, because we have previously validated its transfer and functionality from platelet EV to human cells using the same methodology, and because it was virtually 
absent in the HeLa cells we worked with (impossible to detect the endogenous miR-223 by RT-qPCR; Laffont et al., 2013, 2016). The transfer of miRNA miR-223 is likely to modulate immunity and affect cell proliferation, considering that it is an inflammatory oncomiR (a cancer-associated miRNA; Taïbi et al., 2014); the results obtained with miR-223 are likely applicable to any other milk miRNAs. However, the caveats must be considered, that miRNA target prediction tools are limited (Godard and van Eyll, 2015) and do not take into account isomiR sequences (Cloonan et al., 2011; Neilsen et al., 2012; Plé et al., 2012; Tan et al., 2014; Yu et al., 2017a; Nejad et al., 2018), and that milk EV contain numerous other bioactive RNA (pre-miRNA, mRNA, long noncoding RNA, circular RNA, tRNA fragments, and others; Hata et al., 2010; Lässer et al., 2011; Izumi et al., 2012, 2013; Shen et al., 2016; Liu et al., 2019). However, it is important to note that miR223 is not among the most abundant milk miRNAs and that more pronounced effects might be observed when focusing on more abundant milk miRNAs.

Milk EV are also loaded with bioactive proteins and possibly lipids (Boilard, 2018; Benmoussa et al., 2019). It is, therefore, most likely that miRNAs participate in a broader spectrum of effects that can hardly be attributed to a single protein or a single miRNA. The specific effects of milk miRNAs might be investigated in certain Dicer-knockout models in vitro (Kim et al., 2016) or in vivo (McKenna et al., 2010).

Previous reports suggested that certain milk EV were specifically loaded with certain small RNA (Shu et al., 2015; Alsaweed et al., 2016). In this study, we complement this view by including the diversity of EV and miRNA isomiR, which can have different targets and effects compared with the reference miRNA sequences (Cloonan et al., 2011; Neilsen et al., 2012; Plé et al., 2012; Tan et al., 2014; Yu et al., 2017a; Nejad et al., 2018). As an example of this effect, we predicted the target of miR-30a and its isomiR. We found that the miR-30a-iso4 seed region was shifted because of an insertion in its $5^{\prime}$ end, which allowed this isomiR to target a set of genes different than those targeted by the reference miR-30a sequence (Supplemental Figure S2; https://doi.org/10.3168/jds.2019-16880). Notably, in our previous work, we found that a miRNA isomiR with such a shift in its seed region was more potent at regulating a given target gene than the reference miRNA was (Plé et al., 2012). Therefore, we cannot exclude the possibility that the EV subsets present in cow milk, each with different miRNA and isomiR contents, might act in concert and differentially affect recipient cell gene expression in an extraordinarily complex way. Therefore, although it is important to delineate the content of each EV subset in order to understand their nature and origins, it might also be of importance to assess the effects of all the EV subsets combined, to fully understand the effects of milk EV on health and disease.

\section{CONCLUSIONS}

Designed to explore the diversity and complexity of commercial cow milk EV and their small RNA content, this study markedly enriches our knowledge of milk EV, miRNA, and isomiR, and brings further support to the concept of miRNA transfer from cow milk EV to human cells. The exact implications of these findings and their significance in broader biological processes require further investigations, both in vivo and in vitro, which may reveal the molecular and cellular mechanisms underlying milk EV biology.

\section{ACKNOWLEDGMENTS}

This work was supported by the Fonds de recherche du Québec-Santé (Montréal, Canada), through PhD Studentship Award No. 262093 (to A. B.), and the Canadian Institutes of Health Research (CIHR, Ottawa, Canada) Grants No. IG1-134171, MOP-137081 (through the Institute of Genetics) and PJT-165806 (to P. P.). The authors declare no conflicts of interest.

\section{REFERENCES}

Alsaweed, M., P. E. Hartmann, D. T. Geddes, and F. Kakulas. 2015. MicroRNAs in breastmilk and the lactating breast: Potential immunoprotectors and developmental regulators for the infant and the mother. Int. J. Environ. Res. Public Health 12:13981-14020.

Alsaweed, M., C. T. Lai, P. E. Hartmann, D. T. Geddes, and F. Kakulas. 2016. Human milk miRNAs primarily originate from the mammary gland resulting in unique miRNA profiles of fractionated milk. Sci. Rep. 6:20680.

Arntz, O. J., B. C. Pieters, M. C. Oliveira, M. G. Broeren, M. B. Bennink, M. de Vries, P. L. van Lent, M. I. Koenders, W. B. van den Berg, P. M. van der Kraan, and F. A. van de Loo. 2015. Oral administration of bovine milk derived extracellular vesicles attenuates arthritis in two mouse models. Mol. Nutr. Food Res. 59:1701-1712.

Baier, S., K. Howard, J. Cui, J. Shu, and J. Zempleni. 2015. MicroRNAs in chicken eggs are bioavailable in healthy adults and can modulate mRNA expression in peripheral blood mononuclear cells. FASEB J. 29(Supplement 1):LB322.

Baier, S. R., C. Nguyen, F. Xie, J. R. Wood, and J. Zempleni. 2014. MicroRNAs are absorbed in biologically meaningful amounts from nutritionally relevant doses of cow milk and affect gene expression in peripheral blood mononuclear cells, HEK-293 kidney cell cultures, and mouse livers. J. Nutr. 144:1495-1500.

Ballard, O., and A. L. Morrow. 2013. Human milk composition: Nutrients and bioactive factors. Pediatr. Clin. North Am. 60:49-74.

Bartel, D. P. 2018. Metazoan MicroRNAs. Cell 173:20-51.

Baumgartener, L., C. Olson, and M. Onuma. 1977. Effect of pasteurization and heat treatment on bovine leukemia virus. J. Am. Vet. Med. Assoc. 169:1189-1191.

Benmoussa, A., C. Gotti, S. Bourassa, C. Gilbert, and P. Provost. 2019. Identification of protein markers for extracellular vesicle (EV) subsets in cow's milk. J. Proteomics 192:78-88. 
Benmoussa, A., C. H. Lee, B. Laffont, P. Savard, J. Laugier, E. Boilard, C. Gilbert, I. Fliss, and P. Provost. 2016. Commercial dairy cow milk microRNAs resist digestion under simulated gastrointestinal tract conditions. J. Nutr. 146:2206-2215.

Benmoussa, A., S. Ly, S. T. Shan, J. Laugier, E. Boilard, C. Gilbert, and P. Provost. 2017. A subset of extracellular vesicles carries the bulk of microRNAs in commercial dairy cow's milk. J. Extracell. Vesicles 6:1401897.

Benmoussa, A., and P. Provost. 2019. Milk microRNAs in health and disease. Compr. Rev. Food Sci. Food Saf. 18:703-722.

Berezikov, E. 2011. Evolution of microRNA diversity and regulation in animals. Nat. Rev. Genet. 12:846-860.

Betker, J. L., B. M. Angle, M. W. Graner, and T. J. Anchordoquy. 2019. The potential of exosomes from cow milk for oral delivery. J. Pharm. Sci. 108:1496-1505.

Bogahawaththa, D., R. Buckow, J. Chandrapala, and T. Vasiljevic. 2018. Comparison between thermal pasteurization and high pressure processing of bovine skim milk in relation to denaturation and immunogenicity of native milk proteins. Innov. Food Sci. Emerg. Technol. 47:301-308.

Boilard, E. 2018. Extracellular vesicles and their content in bioactive lipid mediators: More than a sack of microRNA. J. Lipid Res. 59:2037-2046.

Bordoni, A., F. Danesi, D. Dardevet, D. Dupont, A. S. Fernandez, D. Gille, C. Nunes Dos Santos, P. Pinto, R. Re, D. Remond, D. R. Shahar, and G. Vergeres. 2017. Dairy products and inflammation: A review of the clinical evidence. Crit. Rev. Food Sci. Nutr. $57: 2497-2525$

Bustin, S. A., V. Benes, J. A. Garson, J. Hellemans, J. Huggett, M. Kubista, R. Mueller, T. Nolan, M. W. Pfaffl, G. L. Shipley, J. Vandesompele, and C. T. Wittwer. 2009. The MIQE guidelines: Minimum information for publication of quantitative real-time PCR experiments. Clin. Chem. 55:611-622.

Chen, X., C. Gao, H. Li, L. Huang, Q. Sun, Y. Dong, C. Tian, S. Gao, H. Dong, D. Guan, X. Hu, S. Zhao, L. Li, L. Zhu, Q. Yan, J. Zhang, K. Zen, and C. Y. Zhang. 2010. Identification and characterization of microRNAs in raw milk during different periods of lactation, commercial fluid, and powdered milk products. Cell Res. 20:1128-1137.

Chiou, N. T., R. Kageyama, and K. M. Ansel. 2018. Selective export into extracellular vesicles and function of tRNA fragments during T cell activation. Cell Rep. 25:3356-3370.e4.

Cloonan, N., S. Wani, Q. Xu, J. Gu, K. Lea, S. Heater, C. Barbacioru, A. L. Steptoe, H. C. Martin, E. Nourbakhsh, K. Krishnan, B. Gardiner, X. Wang, K. Nones, J. A. Steen, N. A. Matigian, D. L. Wood, K. S. Kassahn, N. Waddell, J. Shepherd, C. Lee, J. Ichikawa, K. McKernan, K. Bramlett, S. Kuersten, and S. M. Grimmond. 2011. MicroRNAs and their isomiRs function cooperatively to target common biological pathways. Genome Biol. 12:R126.

Colombo, M., G. Raposo, and C. Théry. 2014. Biogenesis, secretion, and intercellular interactions of exosomes and other extracellular vesicles. Annu. Rev. Cell Dev. Biol. 30:255-289.

Dever, J. T., M. Q. Kemp, A. L. Thompson, H. G. Keller, J. C. Waksmonski, C. D. Scholl, and D. M. Barnes. 2015. Survival and diversity of human homologous dietary microRNAs in conventionally cooked top sirloin and dried bovine tissue extracts. PLoS One 10:e0138275

Elsik, C. G., D. R. Unni, C. M. Diesh, A. Tayal, M. L. Emery, H. N. Nguyen, and D. E. Hagen. 2016. Bovine Genome Database: New tools for gleaning function from the Bos taurus genome. Nucleic Acids Res. 44(D1):D834-D839.

Gebert, L. F. R., and I. J. MacRae. 2019. Regulation of microRNA function in animals. Nat. Rev. Mol. Cell Biol. 20:21-37.

Godard, P., and J. van Eyll. 2015. Pathway analysis from lists of microRNAs: Common pitfalls and alternative strategy. Nucleic Acids Res. 43:3490-3497.

Guo, L., and F. Chen. 2014. A challenge for miRNA: Multiple isomiRs in miRNAomics. Gene 544:1-7.

Hata, T., K. Murakami, H. Nakatani, Y. Yamamoto, T. Matsuda, and N. Aoki. 2010. Isolation of bovine milk-derived microvesicles car- rying mRNAs and microRNAs. Biochem. Biophys. Res. Commun. 396:528-533.

Heintz-Buschart, A., D. Yusuf, A. Kaysen, A. Etheridge, J. V. Fritz, P. May, C. de Beaufort, B. B. Upadhyaya, A. Ghosal, D. J. Galas, and P. Wilmes. 2018. Small RNA profiling of low biomass samples: Identification and removal of contaminants. BMC Biol. 16:52.

Hill, D. R., and D. S. Newburg. 2015. Clinical applications of bioactive milk components. Nutr. Rev. 73:463-476.

Hou, J., X. An, Y. Song, B. Cao, H. Yang, Z. Zhang, W. Shen, and Y. Li. 2017. Detection and comparison of microRNAs in the caprine mammary gland tissues of colostrum and common milk stages. BMC Genet. 18:38.

Izumi, H., N. Kosaka, T. Shimizu, K. Sekine, T. Ochiya, and M. Takase. 2012. Bovine milk contains microRNA and messenger RNA that are stable under degradative conditions. J. Dairy Sci. 95:4831-4841.

Izumi, H., N. Kosaka, T. Shimizu, K. Sekine, T. Ochiya, and M. Takase. 2013. Purification of RNA from milk whey. Methods Mol. Biol. 1024:191-201.

Izumi, H., M. Tsuda, Y. Sato, N. Kosaka, T. Ochiya, H. Iwamoto, K. Namba, and Y. Takeda. 2015. Bovine milk exosomes contain microRNA and mRNA and are taken up by human macrophages. J. Dairy Sci. 98:2920-2933.

Ju, Z., Q. Jiang, G. Liu, X. Wang, G. Luo, Y. Zhang, J. Zhang, J. Zhong, and J. Huang. 2018. Solexa sequencing and custom microRNA chip reveal repertoire of microRNAs in mammary gland of bovine suffering from natural infectious mastitis. Anim. Genet. 49:3-18.

Keam, S. P., and G. Hutvagner. 2015. tRNA-derived fragments (tRFs): Emerging new roles for an ancient RNA in the regulation of gene expression. Life (Basel) 5:1638-1651.

Kim, Y.-K., B. Kim, and V. N. Kim. 2016. Re-evaluation of the roles of DROSHA, Export in 5, and DICER in microRNA biogenesis Proc. Natl. Acad. Sci. USA 113:E1881-E1889.

Kulp, A., and M. J. Kuehn. 2010. Biological functions and biogenesis of secreted bacterial outer membrane vesicles. Annu. Rev. Microbiol. 64:163-184.

Laffont, B., A. Corduan, H. Plé, A. C. Duchez, N. Cloutier, E. Boilard, and P. Provost. 2013. Activated platelets can deliver mRNA regulatory Ago2 microRNA complexes to endothelial cells via microparticles. Blood 122:253-261.

Laffont, B., A. Corduan, M. Rousseau, A. C. Duchez, C. H. Lee, E. Boilard, and P. Provost. 2016. Platelet microparticles reprogram macrophage gene expression and function. Thromb. Haemost. 115:311-323

Lässer, C., V. S. Alikhani, K. Ekström, M. Eldh, P. T. Paredes, A. Bossios, M. Sjöstrand, S. Gabrielsson, J. Lötvall, and H. Valadi. 2011. Human saliva, plasma and breast milk exosomes contain RNA: Uptake by macrophages. J. Transl. Med. 9:9.

Lässer, C., G. V. Shelke, A. Yeri, D. K. Kim, R. Crescitelli, S. Raimondo, M. Sjöstrand, Y. S. Gho, K. Van Keuren Jensen, and J. Lötvall. 2017. Two distinct extracellular RNA signatures released by a single cell type identified by microarray and next-generation sequencing. RNA Biol. 14:58-72.

Lee, C. T., T. Risom, and W. M. Strauss. 2007. Evolutionary conservation of microRNA regulatory circuits: An examination of microRNA gene complexity and conserved microRNA-target interactions through metazoan phylogeny. DNA Cell Biol. 26:209-218.

Li, R., P. L. Dudemaine, X. Zhao, C. Lei, and E. M. Ibeagha-Awemu. 2016. Comparative analysis of the miRNome of bovine milk fat, whey and cells. PLoS One 11:e0154129.

Li, Z., H. Liu, X. Jin, L. Lo, and J. Liu. 2012. Expression profiles of microRNAs from lactating and non-lactating bovine mammary glands and identification of miRNA related to lactation. BMC Genomics 13:731.

Liu, T., Q. Zhang, T. Zhang, C. Li, Y. R. Miao, Q. Li, and A. Y. Guo. 2019. EVmiRNA: A database of miRNA profiling in extracellular vesicles. Nucleic Acids Res. 47(D1):D89-D93.

Luoreng, Z. M., X. P. Wang, C. G. Mei, and L. S. Zan. 2018. Comparison of microRNA profiles between bovine mammary glands 
infected with Staphylococcus aureus and Escherichia coli. Int. J. Biol. Sci. 14:87-99.

Maas, S. L. N., X. O. Breakefield, and A. M. Weaver. 2017. Extracellular vesicles: Unique intercellular delivery vehicles. Trends Cell Biol. 27:172-188.

McKenna, L. B., J. Schug, A. Vourekas, J. B. McKenna, N. C. Bramswig, J. R. Friedman, and K. H. Kaestner. 2010. MicroRNAs control intestinal epithelial differentiation, architecture, and barrier function. Gastroenterology 139:1654-1664.

Melnik, B., and G. Schmitz. 2017a. DNA methyltransferase 1-targeting miRNA-148a of dairy milk: A potential bioactive modifier of the human epigenome. Functional Foods in Health and Disease 7:671-687.

Melnik, B. C., S. M. John, and G. Schmitz. 2013. Milk is not just food but most likely a genetic transfection system activating mTORC1 signaling for postnatal growth. Nutr. J. 12:103.

Melnik, B. C., and G. Schmitz. 2017b. MicroRNAs: Milk's epigenetic regulators. Best Pract. Res. Clin. Endocrinol. Metab. 31:427-442.

Neilsen, C. T., G. J. Goodall, and C. P. Bracken. 2012. IsomiRsThe overlooked repertoire in the dynamic microRNAome. Trends Genet. 28:544-549.

Nejad, C., K. A. Pillman, K. J. Siddle, G. Pépin, M. L. Anko, C. E. McCoy, T. H. Beilharz, L. Quintana-Murci, G. J. Goodall, C. P. Bracken, and M. P. Gantier. 2018. miR-222 isoforms are differentially regulated by type-I interferon. RNA 24:332-341.

Olsen, S. F., T. I. Halldorsson, W. C. Willett, V. K. Knudsen, M. W. Gillman, T. B. Mikkelsen, and J. Olsen. 2007. Milk consumption during pregnancy is associated with increased infant size at birth: Prospective cohort study. Am. J. Clin. Nutr. 86:1104-1110.

Pang, M., X. Xie, H. Bao, L. Sun, T. He, H. Zhao, Y. Zhou, L. Zhang, H. Zhang, R. Wei, K. Xie, and R. Wang. 2018. Insights into the bovine milk microbiota in dairy farms with different incidence rates of subclinical mastitis. Front. Microbiol. 9:2379.

Pathan, M., P. Fonseka, S. V. Chitti, T. Kang, R. Sanwlani, J. Van Deun, A. Hendrix, and S. Mathivanan. 2019. Vesiclepedia 2019: A compendium of RNA, proteins, lipids and metabolites in extracellular vesicles. Nucleic Acids Res. 47(D1):D516-D519.

Pépin, G., M. P. Perron, and P. Provost. 2012. Regulation of human Dicer by the resident ER membrane protein CLIMP-63. Nucleic Acids Res. 40:11603-11617.

Pieters, B. C., O. J. Arntz, M. B. Bennink, M. G. Broeren, A. P. van Caam, M. I. Koenders, P. L. van Lent, W. B. van den Berg, M. de Vries, P. M. van der Kraan, and F. A. van de Loo. 2015. Commercial cow milk contains physically stable extracellular vesicles expressing immunoregulatory TGF-beta. PLoS One 10:e0121123.

Plé, H., P. Landry, A. Benham, C. Coarfa, P. H. Gunaratne, and P. Provost. 2012. The repertoire and features of human platelet microRNAs. PLoS One 7:e50746.

Rani, P., M. Vashisht, N. Golla, S. Shandilya, S. K. Onteru, and D. Singh. 2017. Milk miRNAs encapsulated in exosomes are stable to human digestion and permeable to intestinal barrier in vitro. J. Funct. Foods 34:431-439.

Reinhardt, T. A., J. D. Lippolis, B. J. Nonnecke, and R. E. Sacco. 2012. Bovine milk exosome proteome. J. Proteomics 75:1486-1492.

Schwarzenbach, H., A. M. da Silva, G. Calin, and K. Pantel. 2015. Data normalization strategies for microRNA quantification. Clin. Chem. 61:1333-1342.

Shen, B., L. Zhang, C. Lian, C. Lu, Y. Zhang, Q. Pan, R. Yang, and Z. Zhao. 2016. Deep sequencing and screening of differentially expressed microRNAs related to milk fat metabolism in bovine primary mammary epithelial cells. Int. J. Mol. Sci. 17:200.

Shu, J., K. Chiang, J. Zempleni, and J. Cui. 2015. Computational characterization of exogenous microRNAs that can be transferred into human circulation. PLoS One 10:e0140587.

Sozańska, B., N. Pearce, K. Dudek, and P. Cullinan. 2013. Consumption of unpasteurized milk and its effects on atopy and asthma in children and adult inhabitants in rural Poland. Allergy 68:644-650.

Sun, J., K. Aswath, S. G. Schroeder, J. D. Lippolis, T. A. Reinhardt, and T. S. Sonstegard. 2015. MicroRNA expression profiles of bo- vine milk exosomes in response to Staphylococcus aureus infection. BMC Genomics 16:806.

Taïbi, F., V. Metzinger-Le Meuth, Z. A. Massy, and L. Metzinger. 2014. miR-223: An inflammatory oncomiR enters the cardiovascular field. Biochim. Biophys. Acta. 1842:1001-1009.

Tan, G. C., E. Chan, A. Molnar, R. Sarkar, D. Alexieva, I. M. Isa, S. Robinson, S. Zhang, P. Ellis, C. F. Langford, P. V. Guillot, A. Chandrashekran, N. M. Fisk, L. Castellano, G. Meister, R. M. Winston, W. Cui, D. Baulcombe, and N. J. Dibb. 2014. 5' isomiR variation is of functional and evolutionary importance. Nucleic Acids Res. 42:9424-9435.

Telonis, A. G., P. Loher, Y. Jing, E. Londin, and I. Rigoutsos. 2015. Beyond the one-locus-one-miRNA paradigm: microRNA isoforms enable deeper insights into breast cancer heterogeneity. Nucleic Acids Res. 43:9158-9175.

Thorning, T. K., A. Raben, T. Tholstrup, S. S. Soedamah-Muthu, I. Givens, and A. Astrup. 2016. Milk and dairy products: Good or bad for human health? An assessment of the totality of scientific evidence. Food Nutr. Res. 60:32527.

Title, A. C., R. Denzler, and M. Stoffel. 2015. Uptake and function studies of maternal milk-derived microRNAs. J. Biol. Chem. 290:23680-23691.

van Herwijnen, M. J., M. I. Zonneveld, S. Goerdayal, E. N. Nolte-'t Hoen, J. Garssen, B. Stahl, A. F. Maarten Altelaar, F. A. Redegeld, and M. H. Wauben. 2016. Comprehensive proteomic analysis of human milk-derived extracellular vesicles unveils a novel functional proteome distinct from other milk components. Mol. Cell. Proteomics 15:3412-3423.

van Niel, G., G. D'Angelo, and G. Raposo. 2018. Shedding light on the cell biology of extracellular vesicles. Nat. Rev. Mol. Cell Biol. 19:213.

Wade, B., M. Cummins, A. Keyburn, and T. M. Crowley. 2016. Isolation and detection of microRNA from the egg of chickens. BMC Res. Notes 9:283.

Wang, X. 2017. Isolation of extracellular vesicles from breast milk. Methods Mol. Biol. 1660:351-353.

Weber, J. A., D. H. Baxter, S. Zhang, D. Y. Huang, K. H. Huang, M. J. Lee, D. J. Galas, and K. Wang. 2010. The microRNA spectrum in 12 body fluids. Clin. Chem. 56:1733-1741.

Wicik, Z., M. Gajewska, A. Majewska, D. Walkiewicz, E. Osinska, and T. Motyl. 2016. Characterization of microRNA profile in mammary tissue of dairy and beef breed heifers. J. Anim. Breed. Genet. 133:31-42.

Wolf, T., S. R. Baier, and J. Zempleni. 2015. The intestinal transport of bovine milk exosomes is mediated by endocytosis in human colon carcinoma Caco-2 Cells and rat small intestinal IEC-6 cells. J. Nutr. 145:2201-2206.

Wu, L., and D. Sun. 2016. Meta-analysis of milk consumption and the risk of cognitive disorders. Nutrients 8:E824.

Yoda, M., D. Cifuentes, N. Izumi, Y. Sakaguchi, T. Suzuki, A. J. Giraldez, and Y. Tomari. 2013. Poly(A)-specific ribonuclease mediates 3'-end trimming of Argonaute2-cleaved precursor microRNAs. Cell Rep. 5:715-726.

Yu, F., K. A. Pillman, C. T. Neilsen, J. Toubia, D. M. Lawrence, A Tsykin, M. P. Gantier, D. F. Callen, G. J. Goodall, and C. P. Bracken. 2017a. Naturally existing isoforms of miR-222 have distinct functions. Nucleic Acids Res. 45:11371-11385.

Yu, S., Z. Zhao, L. Sun, and P. Li. 2017b. Fermentation results in quantitative changes in milk-derived exosomes and different effects on cell growth and survival. J. Agric. Food Chem. 65:1220-1228.

Zempleni, J., A. Aguilar-Lozano, M. Sadri, S. Sukreet, S. Manca, D. Wu, F. Zhou, and E. Mutai. 2017. Biological activities of extracellular vesicles and their cargos from bovine and human milk in humans and implications for infants. J. Nutr. 147:3-10.

\section{ORCIDS}

Patrick Provost () https://orcid.org/0000-0002-6099-6562 